\title{
Subglacial sediment distribution from constrained seismic inversion, using MuLTI software: examples from Midtdalsbreen, Norway
}

\author{
Siobhan F. KILLINGBECK, ${ }^{1}$ Adam D. BOOTH, ${ }^{1}$ Philip W. LIVERMORE, ${ }^{1}$ Landis J. WEST, ${ }^{1}$ \\ Benedict T. I. REINARDY, ${ }^{2}$ Atle NESJE ${ }^{3}$ \\ ${ }^{1}$ School of Earth and Environment, University of Leeds, Woodhouse Lane, Leeds LS2 9JT, UK. \\ E-mail: eespr@leeds.ac.uk \\ ${ }^{2}$ Department of Physical Geography, Stockholm University and Bolin Centre for Climate Research, Stockholm \\ ${ }^{3}$ Department of Earth Science, University of Bergen, Norway
}

\begin{abstract}
Fast ice flow is associated with the deformation of subglacial sediment. Seismic shear velocities, Vs, increase with the rigidity of material and hence can be used to distinguish soft sediment from hard bedrock substrates. Depth profiles of Vs can be obtained from inversions of Rayleigh wave dispersion curves, from passive or active-sources, but these can be highly ambiguous and lack depth sensitivity. Our novel Bayesian transdimensional algorithm, MuLTI, circumvents these issues by adding independent depth constraints to the inversion, also allowing comprehensive uncertainty analysis. We apply MuLTI to the inversion of a Rayleigh wave dataset, acquired using active-source (Multichannel Analysis of Surface Waves) techniques, to characterise sediment distribution beneath the frontal margin of Midtdalsbreen, an outlet of Norway's Hardangerjøkulen ice cap. Ice thickness $(0-20 \mathrm{~m})$ is constrained using co-located GPR data. Outputs from MuLTI suggest that partly-frozen sediment (Vs 500-1000 $\mathrm{m} \mathrm{s}^{-1}$ ), overlying bedrock (Vs 2000-2500 $\mathrm{m} \mathrm{s}^{-1}$ ), is present in patches with a thickness of $\sim 4 \mathrm{~m}$, although this approaches the resolvable limit of our Rayleigh wave frequencies $(14-100 \mathrm{~Hz})$. Uncertainties immediately beneath the glacier bed are $<280 \mathrm{~m} \mathrm{~s}^{-1}$, implying that MuLTI cannot only distinguish bedrock and sediment substrates but does so with an accuracy sufficient for resolving variations in sediment properties.
\end{abstract}

KEYWORDS: glacier geophysics, seismology, subglacial exploration geophysics, subglacial sediments

\section{INTRODUCTION}

The subglacial environment exerts a substantial control over the flow dynamics of glaciers and ice masses (Bell, 2008; Siegert and others, 2018). A major uncertainty in ice dynamic models is the limited understanding of processes at the ice/bed interface and the composition of subglacial material. A significant control on ice motion is whether ice is underlain by the hard or soft substrate, and therefore whether the motion is governed by ice/sediment deformation (Hofstede and others, 2018) or sliding (Stearns and van der Veen, 2018). Such compositional variations are typically parameterised in predictive models by assuming a frictional stress coefficient (Christoffersen and others, 2014; Åkesson and others, 2017), although recent work by Stearns and Van der Veen (2018) highlights the potentially greater influence of effective basal pressure. Where underlain by sediment, the hydrological properties of the subglacial environment, therefore, have a profound effect on glacial flow and require proper consideration in ice dynamic modelling (Kulessa and others, 2017; Siegert and others, 2018).

Quantitative geophysical analysis of subglacial material is typically not straightforward: although many geophysical methods can assess the mechanical properties of glaciers and ice masses, they can be problematic for characterising material much beyond the immediate vicinity $(\sim 2 \mathrm{~m})$ of the glacier bed (Booth and others, 2012). Seismic reflection methods often lack the resolution or signal-to-noise ratio for quantifying subglacial material properties and, for example, may be limited to amplitude-versus-offset (AVO) studies of basal reflectivity (e.g.,
Anandakrishnan, 2003; Booth and others, 2012; Kulessa and others, 2017). Seismic refraction methods are limited by their low depth penetration into subglacial material (e.g., Thiel and Ostenso, 1961; Bentley and Kohnen, 1976; King and Jarvis, 2007); refraction interpretations are impeded since an ice/sediment interface typically represents a velocity reduction, hence critical refraction will not occur and a head-wave will not be generated. Ground penetrating radar (GPR) methods are well suited to characterising englacial properties (e.g., Murray and others, 2007; Young Kim and others, 2010; Booth and others, 2013; Lindbäck and others, 2018), but glacier bed reflectivity and high attenuation within the ice column limits the utility of subglacial radar sampling.

Dispersion curve analysis of surface (Rayleigh) waves presents an alternative method for characterising seismic properties of basal material, for both passive- or active-sources, by constraining the variation of shear wave velocity $(\mathrm{Vs})$ with depth (Xia and others, 2003). Rayleigh waves are a form of seismic wave that travel along the ground-surface, termed 'groundroll' in reflection seismology and although often considered as noise, they contain $\sim 2 / 3$ of the total energy of a typical surface source (Richart and others, 1970). In passive seismology, Picotti and others (2017) used the horizontalto-vertical spectral ratio (HVSR) technique to map glacier and ice-sheet thicknesses and, in certain conditions, obtain reliable estimates of the basal seismic properties. Preiswerk and Walter (2018) used high frequency ( $>2 \mathrm{~Hz})$ ambient seismic noise, collected on alpine glaciers, to estimate ice thickness and infer potential bed properties. These techniques 
are analogous to those used to determine the properties of the Earth's deep interior (Shen and others, 2018). Within active seismology, the use of Rayleigh wave dispersion curves is termed 'Multichannel Analysis of Surface Waves' (MASW).

Regardless of the source of the dispersion curve, characterising Vs offers a promising means of distinguishing material within the subglacial environment, since shear wave properties vary with rigidity (shear modulus). Various researchers have used Vs to distinguish between hard and soft glacier substrates (Picotti and others, 2015), or the boundary between frozen and unfrozen zones within sediment (Tsuji and others, 2012). Zimmerman and King (1986) showed that seismic velocities vary significantly with the degree of porefluid freezing, with Vs increasing by as much as $90 \%$ as pore water freezes (Johansen and others, 2003). Current applications of MASW methods within cryosphere studies include: identifying $\mathrm{Vs}$ and density structure within firn (Armstrong, 2009; Diez and others, 2014), identifying velocity (Vs) structure within shallow ice (Tsoflias and others, 2008b; Young Kim and others, 2010), monitoring and mapping embedded low Vs zones in permafrost areas (Dou and Ajo-Franklin, 2014) and identifying unfrozen zones in subglacial sediments (Tsuji and others, 2012).

However, Vs depth profiles obtained from MASW suffer from poor depth resolution (Foti and others, 2015). Even for the active-source case, using frequencies that are typically higher than for passive seismology, vertical resolution can be limited to $\sim 10 \mathrm{~m}$. Indeed, at a fundamental level, the inversion of dispersion curves is also nonunique: many profiles of $\mathrm{Vs}$ (spanning a disparate set of physical structures) may be consistent with the observed data within the error tolerance. These limitations can be mitigated by constraining the MASW inversion using independent and complementary information, in our case the high-resolution determination of internal horizons using co-located GPR surveys, which vastly reduces the space of acceptable models with an associated marked increase in vertical resolution. Key to this method is that the relevant subsurface horizons (e.g., the snow ice surface and the glacier bed) represent contrasts in both electromagnetic and elastic properties.

A recently developed method for depth-constrained MASW inversion, MuLTI (Multimodal Layered Transdimensional Inversion; Killingbeck and others, 2018) is applied in this paper to characterise the subglacial environment. We invert surface wave dispersion curves to evaluate the variation of Vs with depth and assess its accuracy and uncertainty. Following a synthetic study, we analyse a combined MASW-GPR dataset acquired using an active source on Midtdalsbreen, an outlet glacier of Norway's Hardangerjøkulen ice cap. Although applied here to active-source data, the seismic data enters MuLTI only through a dispersion curve, implying that MuLTI is equally valuable as a tool for passive-source seismology with associated depth constraints (which can be from any independent source: e.g., airborne radar or borehole control). Thus, MuLTI is a novel methodology for investigating the subglacial environment for a range of glacier settings and seismic data types.

\section{METHOD}

\section{Multichannel analysis of surface waves}

MASW surveys use an array of geophones in-line with an active seismic source located on the ground-surface, similar to the acquisition performed for a 2-D seismic reflection survey. The original field records, in the time-space domain, are transformed into the frequency-wavenumber domain, where the dispersive pattern of the Rayleigh waves can be determined by picking the spectral maximum (Park and others, 1998).

The above process requires the following detailed steps. Dispersion curves are calculated from the seismic data using common midpoint cross-correlation (CMPCC) gathers (Hayashi and Suzuki, 2004) and the MASW method introduced by Park and others (1999). CMPCC gathers are created by cross-correlating every pair of traces in each shot gather before sorting into CMP gathers. In each CMP gather, the equally spaced traces were stacked in the time domain to yield CMPCC gathers. To image dispersion curves in the phase velocity-frequency domain, phases of the cross-correlated data were shifted and stacked in the frequency domain, as described in Park and others (1999).

The dispersion curve depends upon the near-surface elastic properties (compressional wave velocity $(\mathrm{V} p)$, Vs and density), assumed horizontally homogeneous beneath the geophone spread, although with the strongest sensitivity to Vs (Xia and others, 2003). The frequency range over which phase velocity is considered reliable corresponds to the minimum and maximum wavelengths recorded. For any given frequency $(f)$, the wavelength $(\lambda)$ is specified as

$$
\lambda=\frac{P V(f)}{f}
$$

where $P V$ is the phase velocity of any frequency component (Stokoe and others, 1994). The resolvable scale of a given frequency component, $L$, is $\sim \lambda / 3$ (Gazetas, 1982), implying that the finite bandwidth $f_{\min }$ to $f_{\max }$ is associated with a range of resolution from $L_{\max } \geq L \geq L_{\min }$, where $L_{\min }$ is the thinnest resolvable layer and $L_{\max }$ is the maximum resolvable depth. This maximum depth is considered conservative, as other researchers (e.g., Park and others, 1999; Tsuji and others, 2012) base this estimate on a $\lambda / 2$ approximation. However, MuLTI incorporates additional independent depth constraints (elaborated in the next section) which widen these bounds and improves the resolution beyond what is possible with surface waves alone (Killingbeck and others, 2018). The useful bandwidth of the survey depends on the signal-tonoise ratio in the dataset, the frequency output of the source, and the length of the survey line. A long survey line is favourable for long wavelengths and hence large $L_{\max }$ but this risks invalidating the assumption of horizontal homogeneity; furthermore, lateral resolution is governed by the range of offsets in each CMPCC gather, hence longer offsets imply greater smearing of horizontal structure (Park, 2005). However, the resolution of dispersion curves improves as the ratio of wavelength to source-receiver offset increases; hence, for any fixed geophone spread, the low frequencies have a poorer resolution in the dispersion image and their interpretation is less precise (Park and others, 2001).

In layered media, inversion for subsurface structure is complicated by the fact that the observed dispersion curve is the combined effect of the different modes of propagation (Foti and others, 2015), ultimately filtered by the physical survey itself which depends upon the survey design parameters. To ensure a good fit, models need to account for not only the fundamental mode (Park and others, 1999) but 
all its higher-order harmonics, referred to as 'modes' of propagation. Early models of surface wave inversion only considered the fundamental mode with simple near-surface environments (Xia and others, 1999). However, higher order modes have shown to dominate in several types of velocity structures, for example when a high-velocity layer overlays a low-velocity layer (Gucunski and Woods, 1992). Therefore multimodal analysis of surface waves is important when anticipating these complex velocity profiles. Our MuLTI algorithm is compatible with such multimodal inversions.

\section{MuLTI}

MuLTI is a Bayesian inversion method that seeks to determine the posterior distribution of $\mathrm{Vs}$, as a function of depth, for a prescribed profile of $V p$ and density, which is fully described in Killingbeck and others (2018). The method does not require the number of subsurface layers to be fixed but rather, in a 'transdimensional' framework, allows the data to self-determine the required complexity of the distribution (e.g., Bodin and Sambridge, 2009; Bodin and others, 2012; Livermore and others, 2018). Its particular utility here is the ability to include subsurface depth constraints, mitigating poor resolution and nonuniqueness of inversions from surface wave dispersion curves alone.

MuLTI is initiated with frequency-phase velocity picks of Rayleigh wave dispersion curves, together with a measure of their uncertainty derived from the half width of the dispersion curve. The depth constraints determined here from GPR data fix particular layer boundaries in the inversion, a selfconsistent procedure as the GPR-derived depths are accurate to the decimeter scale: about a factor of 100 more accurate than the sensitivity of the Rayleigh waves.

Figure 1 illustrates MuLTI's model geometry and shows schematic differences between the unconstrained (Fig. 1a) and depth-constrained (Fig. 1b) cases. If no depth constraints of the subsurface interfaces are available, the unconstrained substructure is characterised (before the introduction of seismic data) by wide bounds on Vs (e.g., Vs between $\sim 200$ and $2800 \mathrm{~m} \mathrm{~s}^{-1}$ ). However, when using co-located GPR data, layer boundaries (e.g., snow/ice) can be identified and the constraints on Vs can be tightened assuming each layer can be attributed to a known material. For example, in this paper, we assume that the upper two layers within the glacier are snow and ice, each with known depth and assumed Vs range (500-1700 $\mathrm{m} \mathrm{s}^{-1}$ for the snow layer and $1700-1950 \mathrm{~m} \mathrm{~s}^{-1}$ for the ice layer), thus significantly reducing the model parameter space.

MuLTI uses the Geopsy theoretical modal dispersion curve algorithm of Wathelet and others (2004), Wathelet (2005) as a forward model to compare any proposed substructure model to the observed data (picked Rayleigh wave dispersion curve). It numerically approximates the posterior distribution by an ensemble of models (a Markov chain), traversing the space of admissible models (shaded boxes shown in Fig. 1), sampling the models with greater likelihood more often. Provided the ensemble size is large enough, the statistics of the ensemble will converge to those of the underlying posterior distribution. MuLTI produces a variety of diagnostic statistics of the Vs ensemble that can be analysed to quantify uncertainty in the subsurface properties. In our analysis, we mainly use the mode and average $\mathrm{Vs}$ profiles to visualize our preferred structure, along with the $95 \%$ credible interval as an estimate of uncertainty.

\section{FIELD SITE: MIDTDALSBREEN}

Midtdalsbreen, $6.8 \mathrm{~km}^{2}$ in area, is a NE-flowing outlet glacier of the Hardangerjøkulen ice cap in central-southern Norway $\left(60.59^{\circ} \mathrm{N}, 7.52^{\circ} \mathrm{E}\right.$; Fig. 2). Hardangerjøkulen is Norway's 6th largest glacier $\left(71.28 \mathrm{~km}^{2}\right.$ ) (Andreassen and Winsvold, 2012) and is an important water source for local river catchments. Annual glacier length measurements performed by A. Nesje between 1982 and 2018 show that the front of a Without GPR Constraints

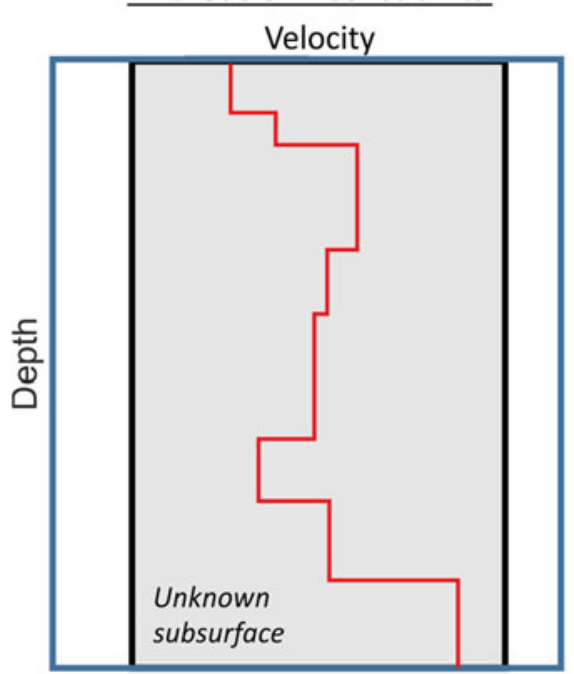

Seismic velocity structure With GPR Constraints

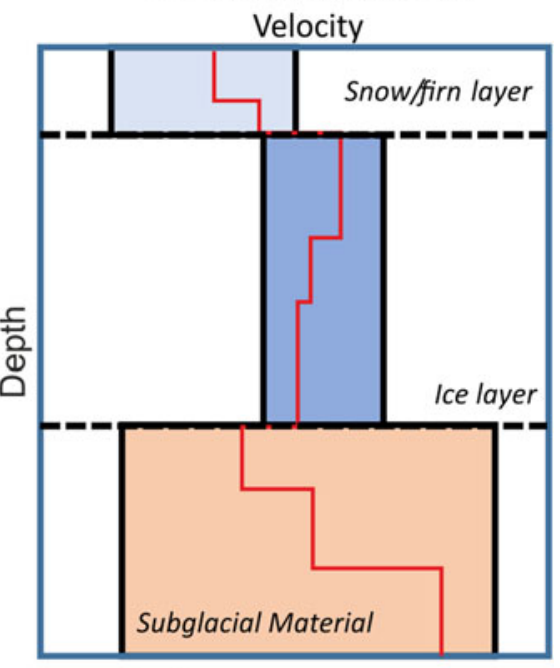
Space of admissible models $\square \square \square \square$

Fig. 1. Illustration of MuLTI's model parameterisation comparing (a) a 1-layer model with no internal layers and (b) a GPR-determined threelayer structure assuming different ranges of Vs within each layer. Shaded boxes indicate the range of possible Vs values. Figure adapted from Killingbeck and others (2018). 


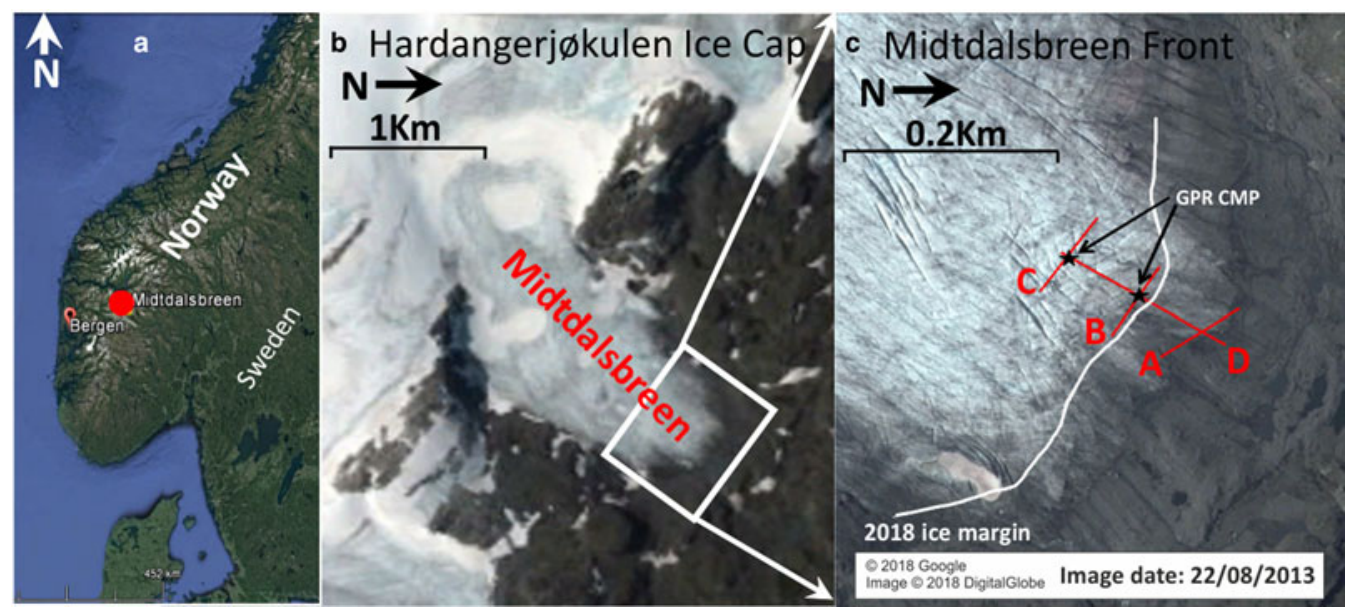

Fig. 2. (a) Location of Hardangerjøkulen ice cap, South Norway. (b) Google Earth image of Midtdalsbreen, an outlet glacier of the Hardangerjøkulen ice cap. (c) Survey lines acquired during the 2018 field season at the front of Midtdalsbreen. Google Earth satellite images taken in 2013. Note that (b) and (c) are orientated away from north to enable optimal data comparison in later figures.

Midtdalsbreen advanced $36 \mathrm{~m}$ between 1982 and 2001, but retreated 219 m between 2001 and 2018 (e.g., nve.no/hydrologi/bre; Reinardy and others, 2019), thus exposing material recently melted out from beneath the glacier. At the time of acquisition, April-May 2018, the subsurface comprised snow ( 2-4 m thick) overlying a varying thickness $(0-25$ $\mathrm{m})$ of glacier ice and a substrate of unknown subglacial material. Midtdalsbreen is well-suited to methodological development since it is both logistically accessible and has a simple wedge-shaped profile (Fig. 3), which is valuable for this study since ice thicknesses show little cross-glacier variation.

Previous GPR data acquisitions show the glacier to have a $40 \mathrm{~m}$ wide cold-ice zone within the majority of the glacier tongue, where ice thickness is $<10 \mathrm{~m}$ (Reinardy and others, 2019). The glacier thickens beyond its tongue and primarily consists of warm ice within the ablation area surveyed in this study. Midtdalsbreen is surrounded by mountains of phyllite and crystalline granite and gneiss. Little Ice Age marginal moraines (post-1750 CE) on the glacier foreland primarily consist of subglacial traction till with both granite, gneiss and phyllite clasts indicating the glacier has a debris-rich basal ice layer probably underlain by sediments and areas of eroded subglacial bedrock (Reinardy and others, 2013).

Several studies have inferred subglacial erosion, transport and depositional processes at Midtdalsbreen from sedimentological and geomorphological observations made in the foreland (Andersen and Sollid, 1971; Etzelmüller and Hagen, 2005; Reinardy and others, 2013, 2019; Willis and others, 2012). Repeated observations indicate $>50 \mathrm{~cm}$ thick sequences of highly saturated till, clay to silt-rich deposits linked to ponding meltwater, and comparatively lower volumes of sand/gravel meltwater stream deposits along with highly polished and striated phyllite. Directly in front of the glacier, end moraines and flutes are occasionally icecored while some till-covered areas of the foreland may also be underlain by dead-ice (ice disconnected from the glacier). However, the distribution of sediments can be

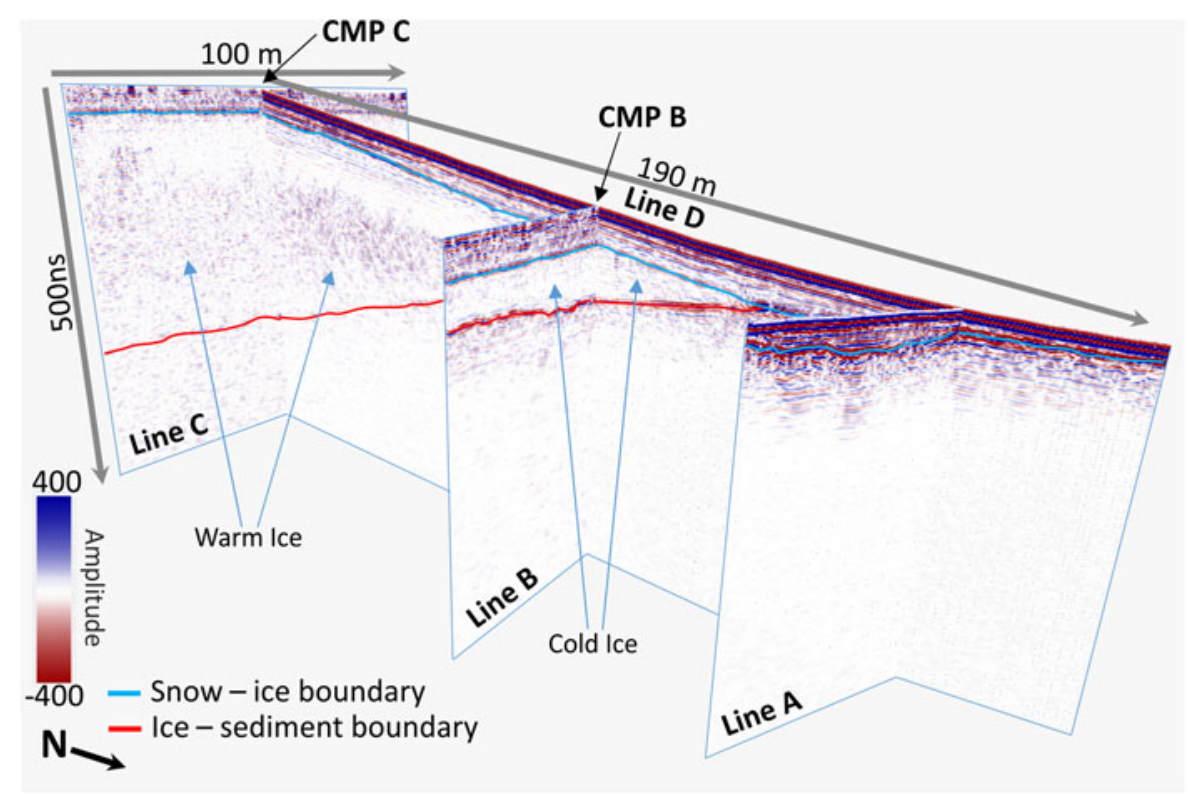

Fig. 3. GPR lines acquired at the front of Midtdalsbreen directly along the 2-D seismic survey lines: A, B, C and D. Snow (blue) and ice (red) horizons were picked in two-way traveltime (TWT). 

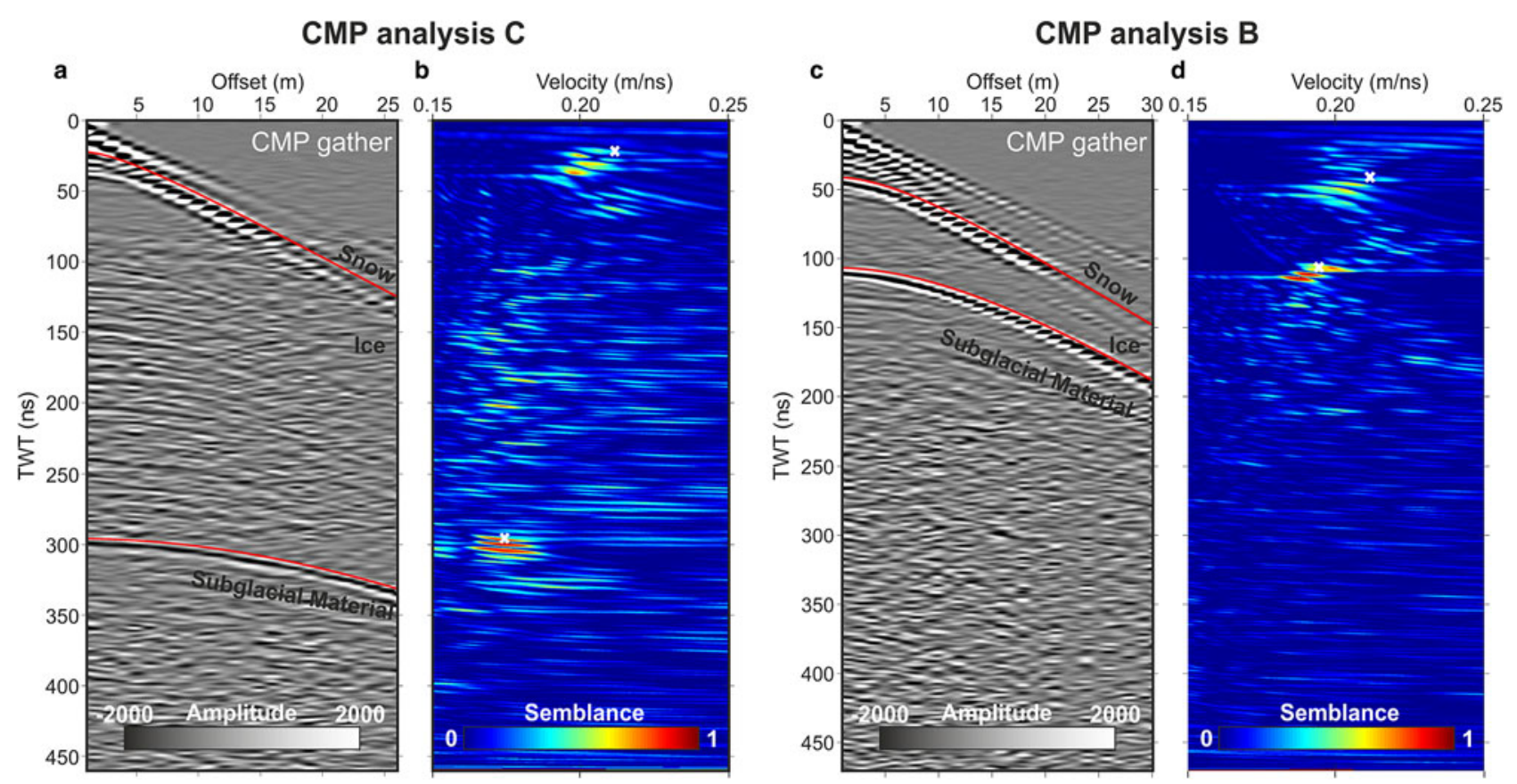

Fig. 4. GPR CMP gathers acquired at the midpoint of lines $B$ and $C$ with corresponding semblance plots in two-way traveltime (TWT). (a) CMP analysis for the midpoint of line C and (b) CMP analysis for midpoint of line B. Picked velocities are highlighted by the white ' $\mathrm{X}$ ' and their corresponding hyperbolae are shown in red (Booth and others, 2010).

highly variable, in both space and time, given the melting of ice cores and the erosion and reworking of sediment by meltwater (Reinardy and others, 2013; 2019). The general lower limit of permafrost in this area is estimated to be $1550 \mathrm{~m}$ a.s. I., however DC-resistivity soundings at $1450 \mathrm{~m}$ a.s.I. and thermistor measurements of cold-ice $\left(<0^{\circ} \mathrm{C}\right)$ at the glacier front of Midtdalsbreen indicate permafrost at lower elevations (Etzelmüller and others, 2003).

To explore the subglacial extent of sediment, Willis and others (2012) investigated the Midtdalsbreen's subglacial drainage system using dye tracing methods. They suggested that the glacier has a split drainage system, with a hydraulically efficient distributed system on the eastern section and an inefficient linked cavity system on the central and western sections. In addition to demonstrating the performance of the MuLTI algorithm, we anticipate that our results will offer additional insight into sediment and ice flow characteristics at the site.

\section{DATA ACQUISITION}

Seismic acquisitions were performed around and over the glacier front (Fig. 2c) with a Geometrics GEODE system and $4810 \mathrm{~Hz}$ vertical-component geophones. For crossglacier lines $\mathrm{A}, \mathrm{B}$ and $\mathrm{C}$, the source and geophone locations had $2 \mathrm{~m}$ intervals; for the down-glacier line $\mathrm{D}$, these were increased to $4 \mathrm{~m}$. GPR profiles were acquired along the length of the seismic lines with Sensors \& Software PulseEKKO PRO unshielded $200 \mathrm{MHz}$ antennas. Figure 3 displays the processed GPR lines and the interpreted position of snow ice and ice-bed horizons. These horizons are generally well defined and can be picked with confidence,

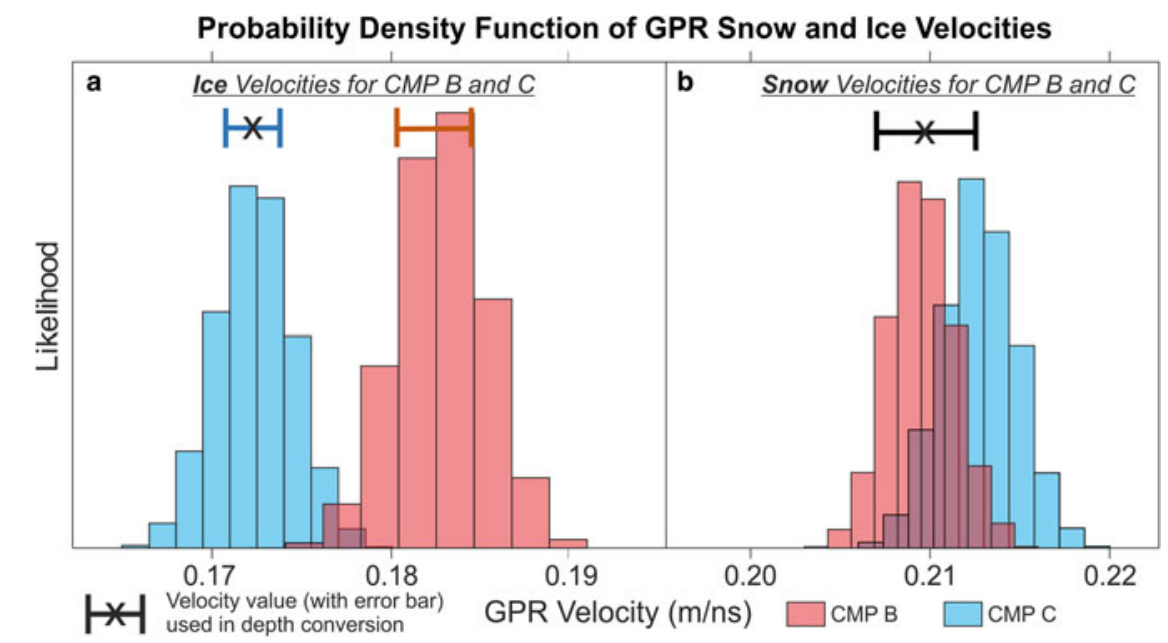

Fig. 5. GPR velocity precision results, using Booth and others (2011) Monte Carlo simulation method, displaying probability density functions of (a) ice and (b) snow GPR velocities derived from CMP B and C. 
although the signal-to-noise ratio at the glacier bed is low below the cold-warm transition surface (where the ice is $>20 \mathrm{~m}$ thick).

The thickness of snow and ice layers was estimated from velocity analysis of GPR common midpoint gathers (CMP) located half way along the seismic spreads B and C (Booth and others, 2011). Figure 4 shows CMP gathers B and C with their associated semblance responses, also marking the picked velocities and their corresponding reflection hyperbolae following velocity corrections using the method described in Booth and others (2010). GPR velocities and their uncertainties are expressed as probability density functions in Figure 5, using a Monte Carlo method (Booth and others, 2011). For the snow layer (Fig. 5b), the CMP analyses yielded a similar median, hence a single average interval velocity $\left(0.2100 \pm 0.0029 \mathrm{~m} \mathrm{~ns}^{-1}\right)$ is assumed in-depth conversions. For the ice layer (Fig. 5a), analysis from CMP B and CMP $\mathrm{C}$ determines differing velocities by $\sim 6 \%$, possibly related to the greater englacial water content at CMP C and therefore more intense scattering at this site. However, the velocity estimate from CMP C $\left(0.1724 \pm 0.0015 \mathrm{~m} \mathrm{~ns}^{-1}\right)$ is more consistent with cold ice from other locations (Murray and others, 2007; Saintenoy and others, 2013; Temminghoff and others, 2018) hence this value is used to evaluate ice thickness.

\section{SYNTHETIC STUDY}

A synthetic study was conducted to validate MuLTI based on a likely target subsurface and to determine inversion parameters for the acquired data. Various 1-D-block models, shown in Fig. 6; a-d (note a-d are unrelated to the seismic lines denoted A-D) were created to represent different glacial and subglacial environments which may be expected at Midtdalsbreen glacier, including snow, glacier ice, water saturated till (low Vs zone) and bedrock. Each layer was populated with $\mathrm{Vp}, \mathrm{Vs}$ and density values representative of each layer (Fig. 6), obtained from example glaciological seismic studies (Peters and others, 2008; Tsoflias and others, 2008a; Podolskiy and Walter, 2016). Inversion parameters are documented in Table S1 in the supplementary material and explained fully in Killingbeck and others (2018).

Synthetic waveforms were calculated from the 1-D block models using the Discrete Wavenumber Method (DWM) (Bouchon and Aki, 1977). This calculates the full waveform, which can be considered an analogue of the observed data in terms of phase velocity and amplitude (Figs 6e-h). The DWM parameters used to calculate the synthetic waveforms are the same as those used for the acquisition of our cross-glacier lines: 48 geophones with $2 \mathrm{~m}$ spacing. The maximum amplitudes of the frequency-phase velocity images were picked to create the Rayleigh wave dispersion curves which were used as input to MuLTI together with an estimate of their uncertainty, $\sigma(f)$, approximated from the half width of the peak, in velocity, at each given frequency (red lines in Figs 6i-l); this is seen to decrease with increasing frequency. The synthetic dispersion images clearly display a fundamental mode along with first and second higher order modes (higher order modes being induced by the low-velocity layer immediately underlying the high-velocity ice). Comparing reference models (Figs $6 \mathrm{i}$ and I), with increasing velocity structure, to the complex velocity models (Figs $6 j$ and $\mathrm{k}$ ), shows that the presence of a sharp decrease in velocity causes a break in the fundamental mode and higher order modes become more dominant. The depth of the velocity change is directly related to the frequency at which the change in dominant mode (from fundamental to higher order) occurs.

The resolution of the dispersion curve, and the precision with which its maxima can be picked is influenced by survey parameters. Longer source-receiver offsets sharpen the dispersion curve and clarify the transition between different modes. However, long offsets in real data become dominated by body waves (e.g., reflections and refractions) hence there is a compromise between dispersion resolution and signal-to-noise ratio (Park and others, 2001; Park, 2005). This issue becomes evident in our real data and is considered in our discussion section.

In this synthetic example, picking of dispersion curves is restricted to frequencies of $14-100 \mathrm{~Hz}$, representative of the bandwidth in our real data. Killingbeck and others (2018) show that including higher frequencies $(>100 \mathrm{~Hz})$ causes instabilities related to the appearance of higherorder modes hence we deliberately omit them in our analysis. Using Eqn (1) and the $\lambda / 3$ wavelength sampling approximation (Gazetas, 1982), the dispersion curves picked in these examples have a thinnest resolvable layer $\left(L_{\min }\right)$ of $3 \mathrm{~m}$ (corresponding to no ice model, Fig. $6 \mathrm{~d}$ ), 4.5

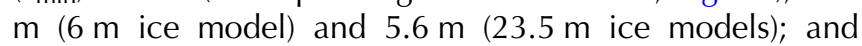
maximum resolvable depth $\left(L_{\max }\right)$ of $30 \mathrm{~m}$ (no ice model), $45 \mathrm{~m}$ (6 m ice model) and $46 \mathrm{~m}$ (23.5 m ice models).

The inversions were run using $\mathrm{Vs}$ boundaries, and corresponding $\mathrm{Vp}$ and density values, set to the parameters stated in Table 1 . Tests on varying $V p$ and density on modal dispersion curves show small variations but these are mostly within the fitting error tolerance $(\sigma)$ used in MuLTI, Figure S1 in the supplementary material. Given the maximum resolvable depth of $46 \mathrm{~m}$ (from purely surface wave data), inversions were performed for a maximum depth of $40 \mathrm{~m}$. To highlight the benefit of additional depth constraints (e.g., derived from GPR), MuLTI is first run for an unconstrained case and thereafter with fixed depths of the snow ice and ice-bed layers. One million iterations were run and found to be sufficient for convergence of the posterior distribution sampled; more detailed inversion parameters used are documented in Table S1 in the supplementary material and explained further in Killingbeck and others (2018)

Posterior Vs distributions produced from MuLTI are shown in Figure 7. The probability density distribution of $\mathrm{Vs}$ profiles within their $95 \%$ credible interval is plotted as coloured contours alongside the true solution (black line). The highest

Table 1. Elastic parameter boundaries applied in MuLTI for the glacier feasibility study. The parameters are taken from Peters and others (2008); Tsoflias and others (2008a); Podolskiy and Walter (2016)

\begin{tabular}{|c|c|c|c|}
\hline \multirow[b]{2}{*}{ Material } & \multicolumn{3}{|c|}{ Elastic Property } \\
\hline & $\begin{array}{c}\text { Density }\left(\mathrm{g} \mathrm{cm}^{-3}\right) \\
\text { Constant }\end{array}$ & $\begin{array}{l}\mathrm{Vp}\left(\mathrm{m} \mathrm{s}^{-1}\right) \\
\text { Constant }\end{array}$ & $\begin{array}{l}\text { Vs }\left(\mathrm{m} \mathrm{s}^{-1}\right) \\
\text { Variable }\end{array}$ \\
\hline Snow & 0.47 & 1800 & 500-1700 \\
\hline Ice & 0.92 & 3810 & 1700-1950 \\
\hline $\begin{array}{l}\text { Subglacial } \\
\text { material }\end{array}$ & 2.5 & 3000 & 200-2800 \\
\hline
\end{tabular}




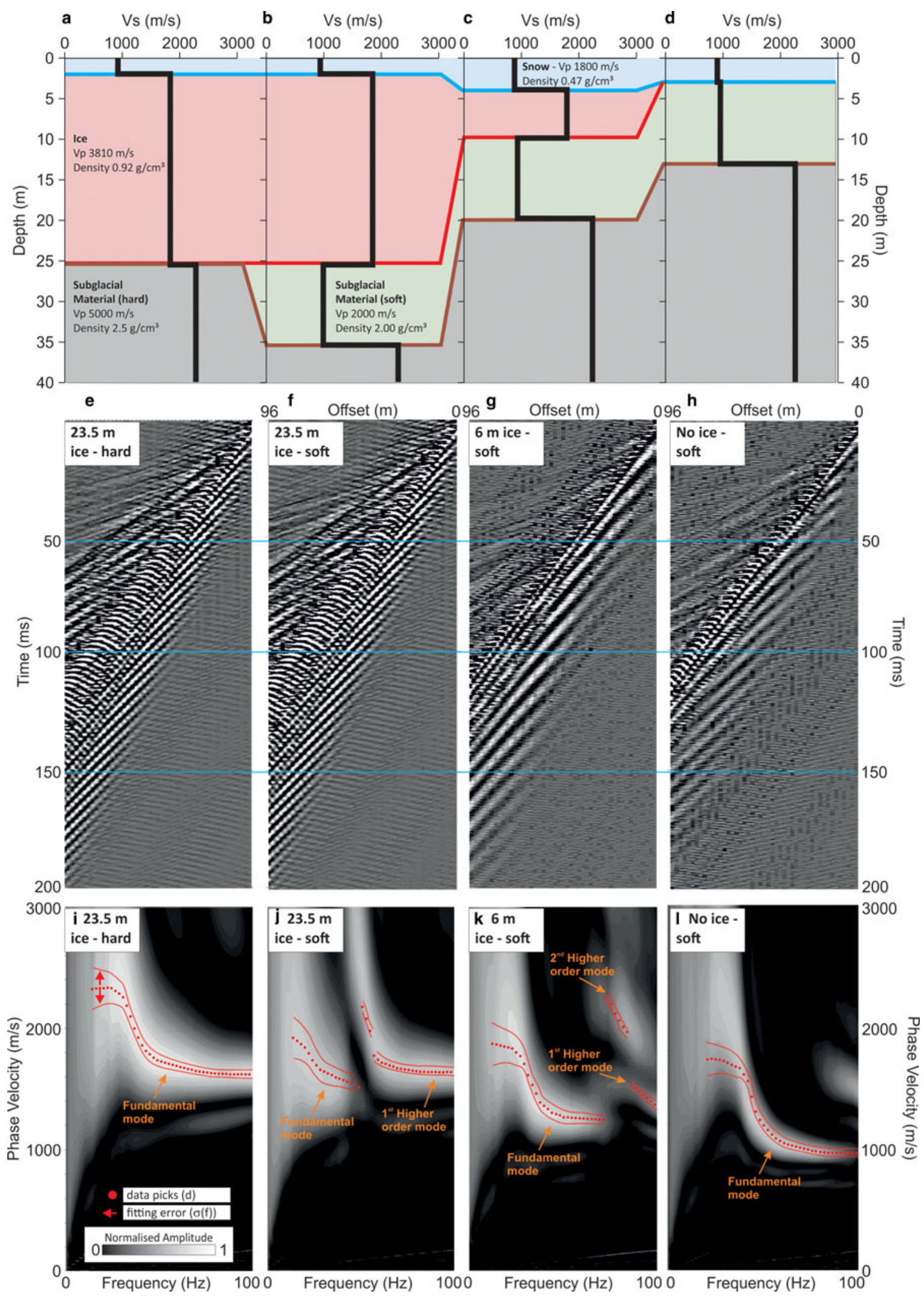

Fig. 6. 1-D block models created to simulate snow and ice thicknesses expected at Lines A, B and C (a-d). Blue, red and brown lines represent base snow, ice and soft substrate boundaries; DWM synthetic wavefield shot gathers (e-h); corresponding dispersion curves picked with an estimate of associated uncertainty derived from the width of the dispersion image (i-l).

density distribution (red) for each depth corresponds to the most likely Vs model. The unconstrained inversions in Figures $7 \mathrm{a}-\mathrm{c}$ show significant deviation between the true model and inversion output, with respective depth-averaged $\mathrm{Vs}$ errors of $680 \mathrm{~m} \mathrm{~s}^{-1}, 1046 \mathrm{~m} \mathrm{~s}^{-1}$ and $567 \mathrm{~m} \mathrm{~s}^{-1}$, respectively, based on the modal model; although the fit is better $\left(240 \mathrm{~m} \mathrm{~s}^{-1}\right.$ error) for $7 \mathrm{~d}$ (and $7 \mathrm{a}$ in the ice layer only), given the simpler underlying parameter distribution, there are multiple $V_{s}$ distribution peaks between 20 and $33 \mathrm{~m}$. The addition of depth constraints improves the 

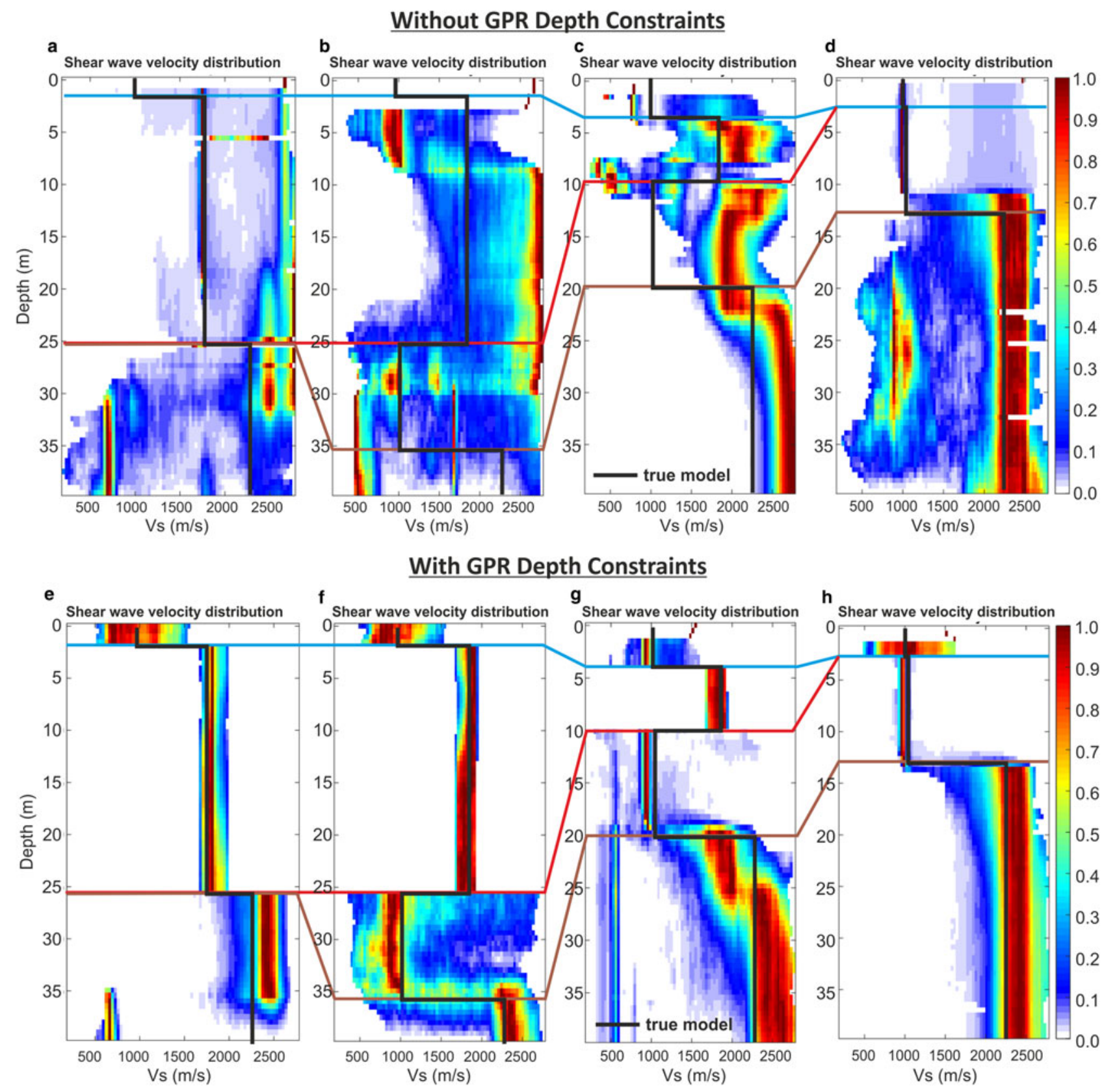

Fig. 7. Posterior Vs distributions determined from MuLTI inversion (a-d) without depth constraints and (e-h) with depth constraints; the models correspond to those shown in Fig. $6 \mathrm{a}-\mathrm{d}$. Colour scale represents the probability density distribution of Vs values within the $95 \%$ credible interval, red highlighting most likely. Black line shows the true synthetic Vs profiles. Blue, red and brown correlation lines highlight the snow, ice and soft substrate depths respectively.

match throughout, and Figures 7e-h show errors of $256 \mathrm{~m}$ $\mathrm{s}^{-1}, 99 \mathrm{~m} \mathrm{~s}^{-1}, 164 \mathrm{~m} \mathrm{~s}^{-1}$ and $138 \mathrm{~m} \mathrm{~s}^{-1}$, respectively (factors of 2.7, 10, 3.5 and 2 improved on their unconstrained equivalents).

More complex synthetic modelling, including an additional ice debris layer (high $\mathrm{Vs}$ ) at the base of the glacier which may not be detected by GPR data, shows MuLTI can reliably resolve unconstrained layers not accounted for in the GPR depth constraints applied within MuLTI (Figure S2 and $\mathrm{S} 3$ in the supplementary material).

This feasibility study demonstrates MuLTI works well for the expected geometries and parameter distributions for the Midtdalsbreen dataset. It also highlights the significant added value of depth constraint when a complex velocity profile is expected.

\section{RESULTS}

\section{1-D shear wave velocity profiles}

We first produced 1-D velocity profiles for CMPCC gathers (Hayashi and Suzuki, 2004) located at the centre of lines A, $B$ and $C$ (Fig. 8). A different range of source-receiver offsets was used in each gather due to differences in data quality and subsurface complexity. This minimises the spatial averaging affect beneath the geophone spread, particularly where the subsurface is not horizontally homogeneous (Park, 2005). Line A shows significant interference between Rayleigh and body waves for offsets $>50 \mathrm{~m}$, whereas colocated GPR data suggest that the subsurface can only be described as 1-D for offsets $<60 \mathrm{~m}$ at Line B. However, data from Line $\mathrm{C}$ suffers from no such restrictions, hence its 

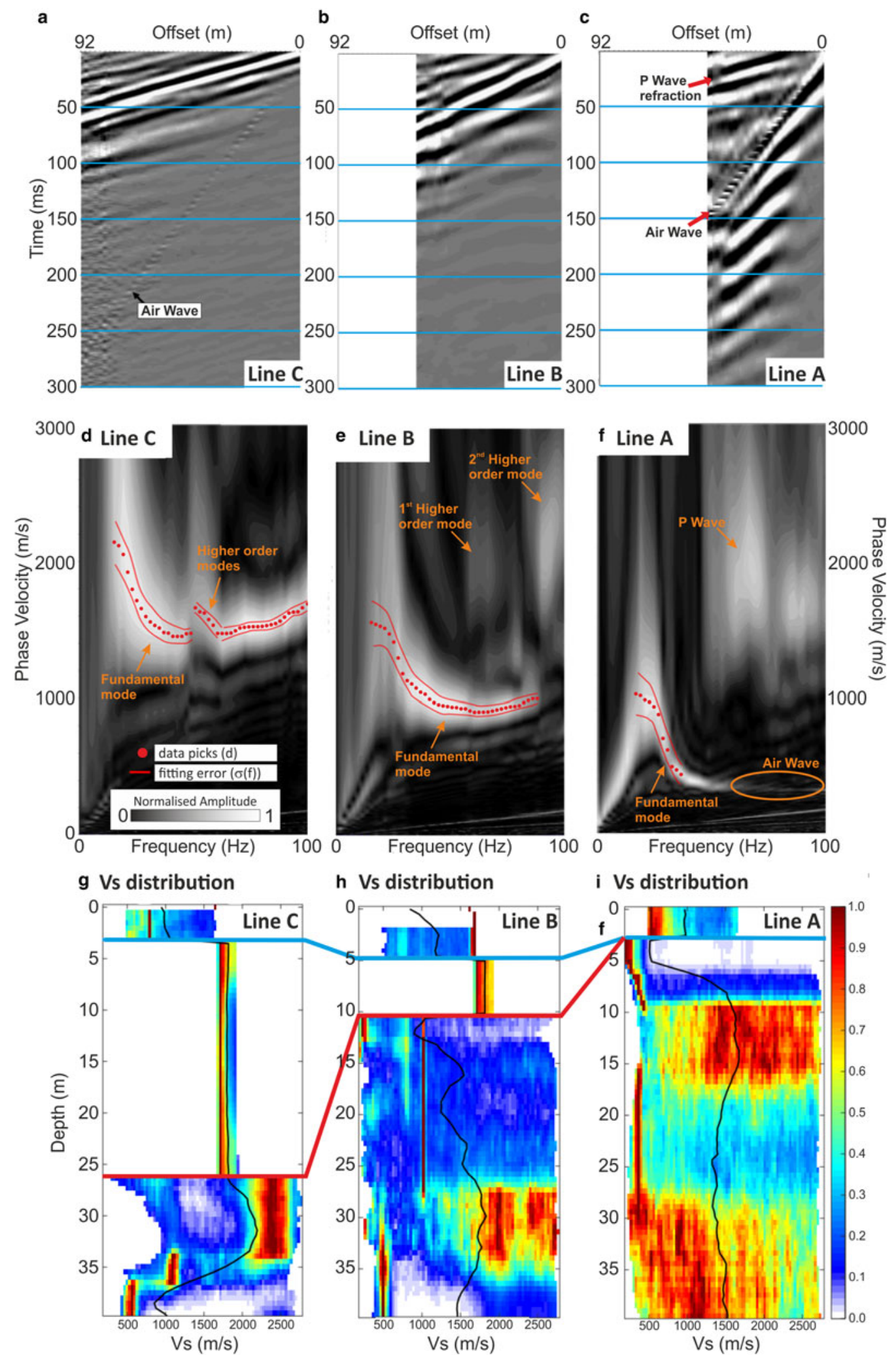

h Vs distribution

i Vs distribution

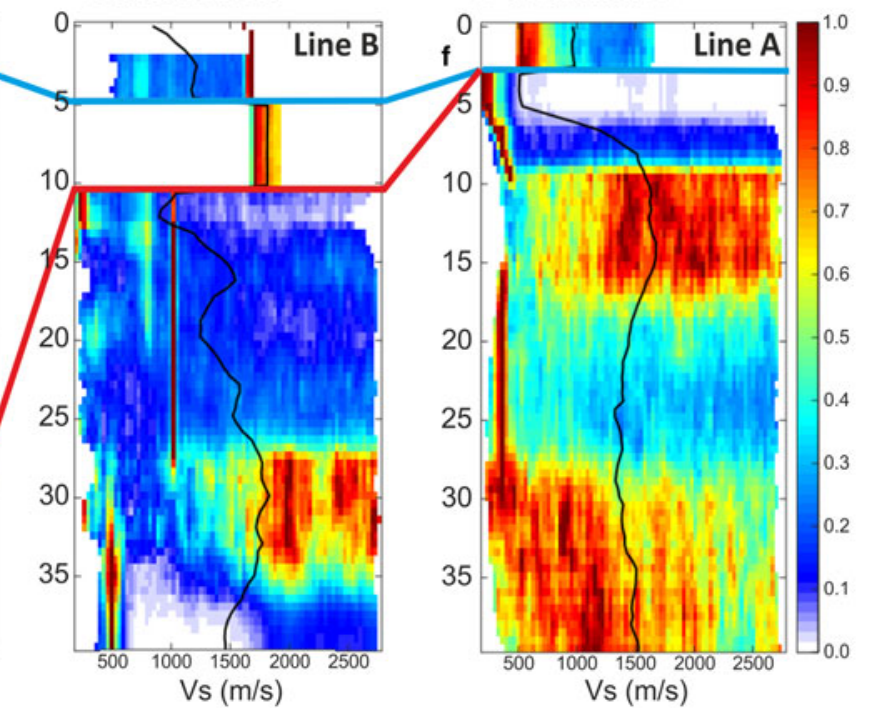

Fig. 8. Mid-line C, B and A CMPCC gathers $(a-c)$, corresponding dispersion images $(d-f)$ and $V s$ distribution profiles (g-i), with the average of the distribution plotted in black.

CMPCC gather uses the full $92 \mathrm{~m}$ offset range for this $1-\mathrm{D}$ analysis.

The dispersion images shown in Figures 8a-c are similar to the synthetic dispersion images (Figs 6i-l) giving an initial insight into the structure expected at Midtdalsbreen. The dispersion curves, which have a high signal-to-noise ratio, are picked for frequencies between 14 and $100 \mathrm{~Hz}$, implying that the thinnest resolvable layers $\left(L_{\min }\right)$ are $4.0 \mathrm{~m}$
(Line A), $3.8 \mathrm{~m}$ (Line B) and $5.7 \mathrm{~m}(\mathrm{C})$ and the maximum resolvable depths $\left(L_{\max }\right)$ are $19.5 \mathrm{~m}($ Line $\mathrm{A}), 33.5 \mathrm{~m}$ (Line B) and $45.7 \mathrm{~m}$ (Line C).

The dispersion picks and their estimated uncertainty were supplied to MuLTI, together with the GPR depth constraints. The inversions used the same parameters used in the synthetic study. Posterior Vs distributions are shown in Figures $8 \mathrm{~g}-\mathrm{i}$, the highest density velocities (coloured red) 


\section{Approximate Depth Resolution}

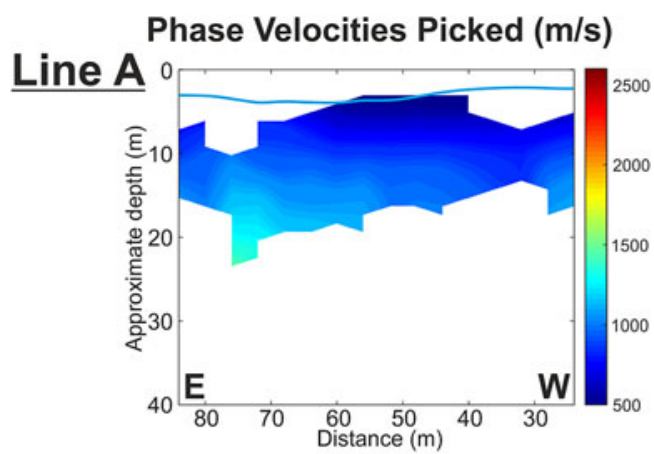

Line B
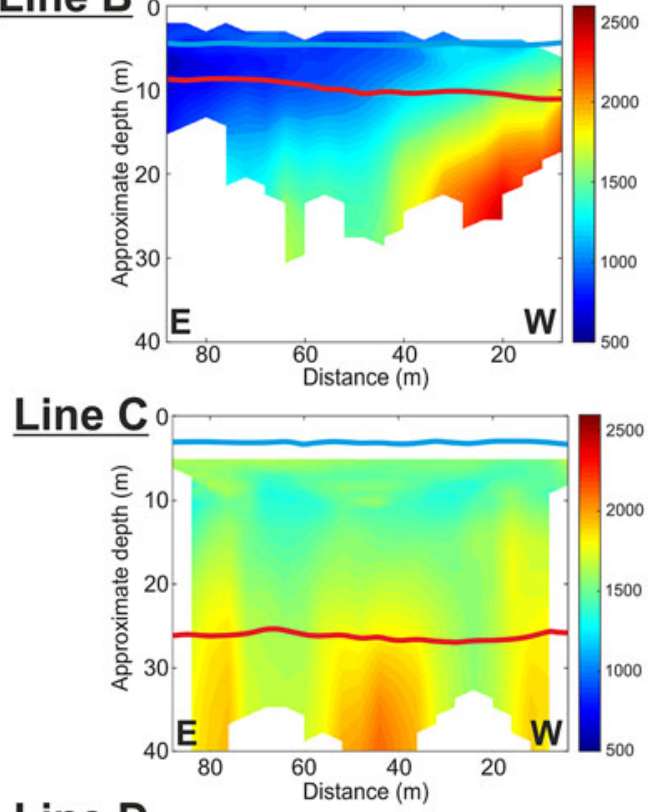

Line D

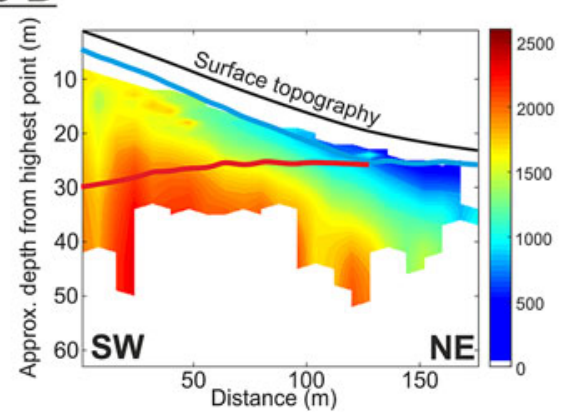

Distribution of Vs
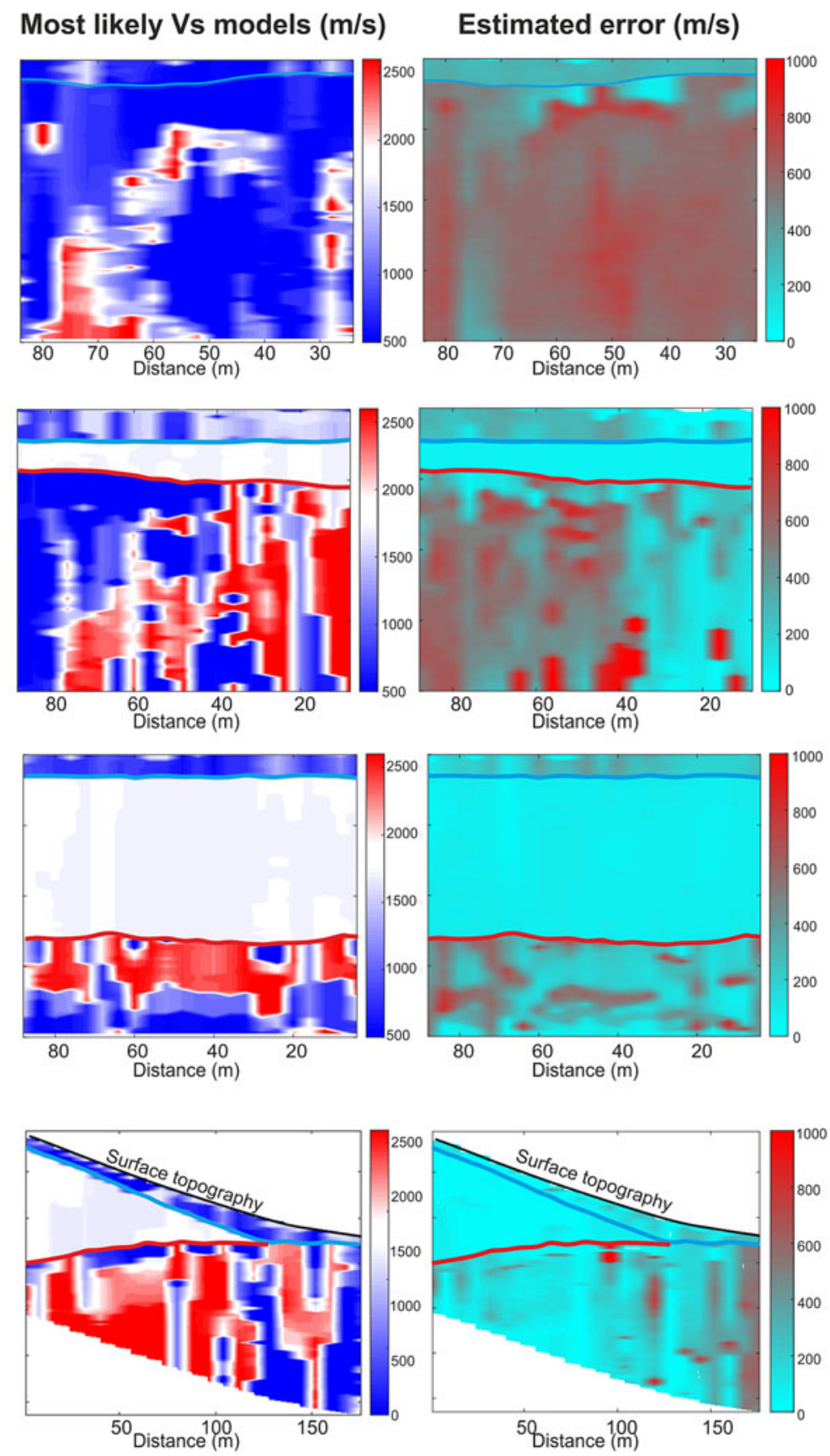

Fig. 9. 2-D inversion outputs for Lines A-D. Left column: approximate 2-D depth resolution, characterised by the range of phase velocity picks. Central column: most likely 2-D Vs profiles output from multiple 1-D MuLTI inversions. Diverging colour scale centred, in white, on Vs of ice (1750-1900 $\mathrm{m} \mathrm{s}^{-1}$ ). Right column: estimated uncertainty (half the interquartile range of the posterior distribution). Snow and ice depth horizons are plotted in blue and red respectively.

corresponding to the most likely (modal) solution. The average solution (black line) is the average of all accepted models, displaying a smoothed Vs solution, and its uncertainty is expressed as one-half of the $95 \%$ credible interval range at each depth. These uncertainties are typically $\pm \sim 600 \mathrm{~m} \mathrm{~s}^{-1}$ for the snow layer, $\pm \sim 120 \mathrm{~m} \mathrm{~s}^{-1}$ for the ice layer and $\pm \sim 1100 \mathrm{~m} \mathrm{~s}^{-1}$ for the subglacial material. The estimated uncertainty for the mode solution is one-half of the interquartile range at each depth, accounting for the skewed probability densities highlighted in Figures $8 \mathrm{~g}-\mathrm{i}$. This convention implies smaller uncertainties: $\pm \sim 250 \mathrm{~m}$ $\mathrm{s}^{-1}$ in the snow layer, $\pm \sim 75 \mathrm{~m} \mathrm{~s}^{-1}$ in the ice layer and $\pm 320-560 \mathrm{~m} \mathrm{~s}^{-1}$ in the subglacial material.

The 1-D inversions show low shear wave velocities, 500-1000 ms ${ }^{-1}$ beneath the constrained snow ice horizon in Line $\mathrm{A}$ and the constrained ice-bed horizon in Line B; both are in turn underlain by a high Vs zone, $2000-2500 \mathrm{~m} \mathrm{~s}^{-1}$. In contrast, high velocities, $\sim 2400 \mathrm{~m}$ $\mathrm{s}^{-1}$, occur directly below the thicker ice in Line C. This analysis suggests a spatially variable pattern of subglacial $V$ s from the front of the glacier to Line C, $150 \mathrm{~m}$ upglacier. 


\section{2-D shear wave velocity profiles}

MuLTI is used to invert multiple independent 1-D dispersion curves picked from all CMPCC gathers along each seismic line. Offsets are limited either to mitigate body wave contamination or prevent lateral smearing (particularly in line D where the thickness of ice decreases along the line and therefore we do not assume lateral homogeneity of $\mathrm{Vs}$ along this line). Dispersion patterns and the implied depth of penetration vary with ice thickness and the likely subglacial Vs, as shown by the depth range of input velocity picks in Figure 9 (leftmost column). These plots represent all 1-D dispersion curves, picked at each CMPCC location along the line, indicate the maximum depth at which inversion results may be considered reliable.

Consistent with initial observations in the 1-D analysis, the 2-D Vs profiles (Fig. 9, central column) highlight a wide range of subglacial Vs values, $\sim 500-2500 \mathrm{~m} \mathrm{~s}^{-1}$. The 2-D profiles highlight spatial variability in $\mathrm{Vs}$ for the study region, both along- and cross- glacier profile (the latter evidenced in particular in Line B). The estimated uncertainties for the mode Vs solutions are displayed in Figure 9 (rightmost column). Consistent with the previous analysis, the estimated uncertainties in the average solution are generally very large, especially where input dispersion curve picks are absent (highlighted in Figure S4 in the supplementary material). The corresponding uncertainties in the mode solution are generally smaller, but still increase at depth, to $\pm \sim 1000 \mathrm{~m}$ $\mathrm{s}^{-1}$ where $\mathrm{Vs}$ constraints are lacking.

\section{INTERPRETATION AND DISCUSSION}

\section{Interpretation of Vs profiles}

Several studies have inferred subglacial erosion, transport and depositional processes at Midtdalsbreen, based on sedimentological and geomorphological evidence from the glacier foreland (Andersen and Sollid, 1971; Etzelmüller and Hagen, 2005; Reinardy and others, 2013, 2019; Willis and others, 2012). However, the type and distribution of subglacial substrate is largely unknown, having not been directly imaged beneath the glacier.

The variability of Vs $\left(500-2500 \mathrm{~m} \mathrm{~s}^{-1}\right)$ in our MASW records points to a complex subglacial structure, comprising local accumulations of bedrock and softer material, potentially permafrost and/or till, overlying bedrock (Fig. 10). We consider the abrupt lateral variations in the outputs to be noise rather than genuine structure and instead interpret the broader variation in lateral and vertical character as representative velocity structure. The lateral resolution in our imaging varies along each line, given the changing offset range in our CMPCC gathers. In Lines $\mathrm{A}-\mathrm{C}$, the limit of lateral resolution is between \pm 4 and $30 \mathrm{~m}$, and is between \pm 8 and $40 \mathrm{~m}$ in Line $\mathrm{D}$; the poorest resolution is observed in the centre of each line, where the offset range in the CMPCC is greatest. The key structures we interpret in Figure 10 are larger in spatial extent than these limits, hence we consider our lateral resolution to be sufficient.

Our slower velocities (500-1000 $\mathrm{m} \mathrm{s}^{-1}$ ) are interpreted to diagnose various types of partially frozen subglacial

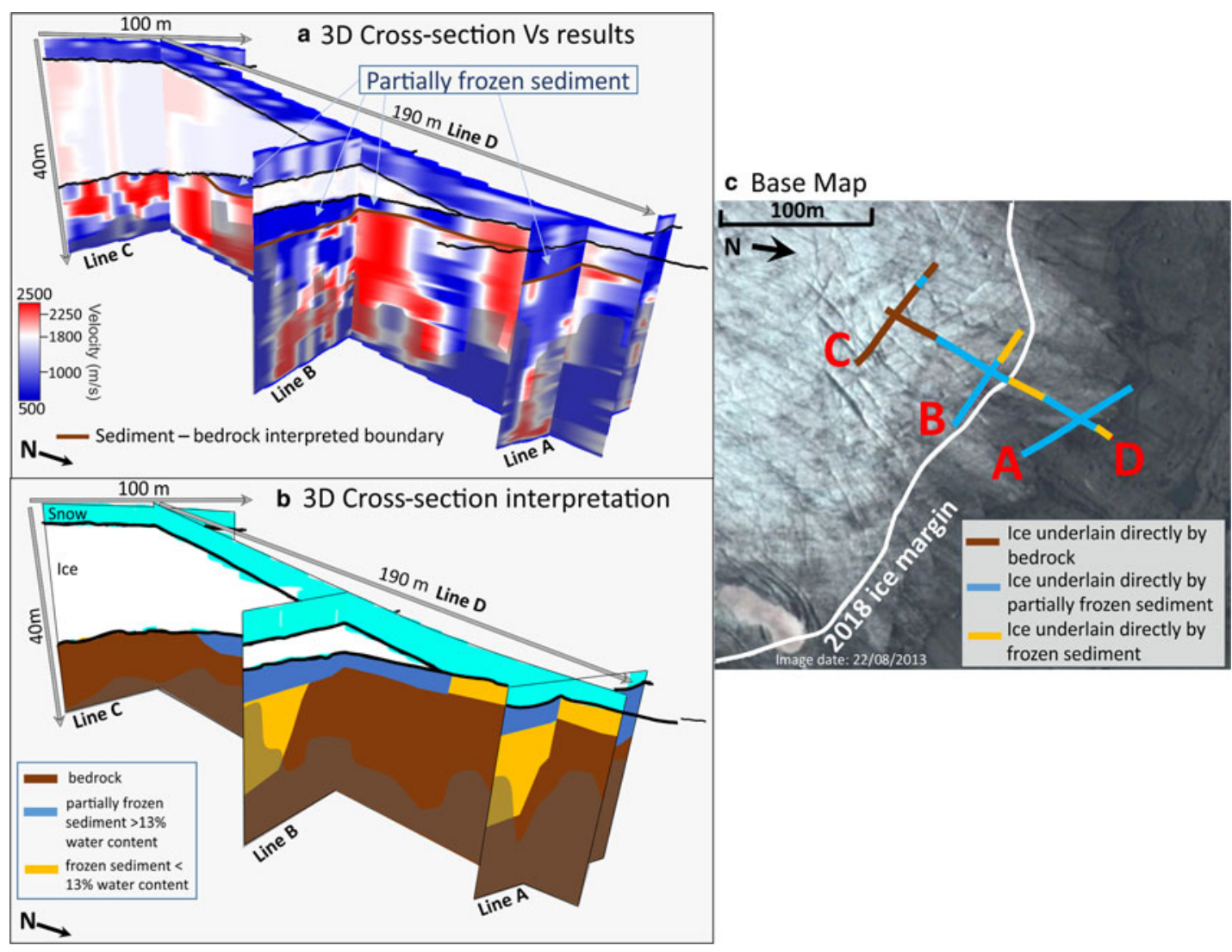

Fig. 10. (a) 3-D cross-section of lines A-D, showing the $\mathrm{V}$ s mode solution and interpreted locations of sediment and bedrock. The black semitransparent overlay shows where $L_{\max }$ is exceeded, hence where results could be unreliable. (b) Schematic 3-D cross-section interpretation of Lines A-D. (c) Base map annotated with line locations and the interpretations from (a). 
sediment, potentially the subglacial continuation of till and silt-rich deposits observed during summer on the glacier foreland. The higher velocities (2000-2500 $\mathrm{m} \mathrm{s}^{-1}$ ) are suggestive of phyllite or granite bedrock, with intermediate values (1000-1700 $\mathrm{m} \mathrm{s}^{-1}$ ) suggestive of frozen zones or weathered bedrock. Kneisel and others (2008) suggest that a small increase in the unfrozen water content of sediment, from 10 to $13 \%$, can cause $V s$ to decrease from 1400 to $600 \mathrm{~m}$ $\mathrm{s}^{-1}$, implying $\mathrm{Vs}$ is potentially a good means of distinguishing frozen and partially-frozen sediment. Although there is potentially some overlap in our velocity ranges, we use:

- $\mathrm{Vs}<1000 \mathrm{~m} \mathrm{~s}^{-1}$ to indicate partly-frozen sediment with water content $>13 \%$,

- $1000<\mathrm{Vs}<2000 \mathrm{~m} \mathrm{~s}^{-1}$ to indicate partly-frozen material with water content $<13 \%$ and

- $\mathrm{Vs}>2000 \mathrm{~m} \mathrm{~s}^{-1}$ to indicate bedrock.

Line $C$ suggests that Midtdalsbreen is directly underlain by bedrock $150 \mathrm{~m}$ from its terminus, but Line D suggests a transition to a sediment under-burden towards the glacier front. The eastern half of Line B, parts of Line D and all of Line $A$ (on the foreland) are likely underlain by soft (partially frozen) sediment deposits (Fig. 10) with a maximum thickness of $4 \mathrm{~m}$. This thickness approaches our limit of vertical resolution, but uncertainties at the associated depth are low: $\pm 100 \mathrm{~m} \mathrm{~s}^{-1}$ in Line $D$ and $\pm 280 \mathrm{~m} \mathrm{~s}^{-1}$ in Lines A-C (Fig. 9). Each inversion also indicates a return to high $V_{s}$ at depth, consistent with underlying bedrock, although the greater uncertainties at these depths would motivate additional validation (e.g., from a lower-frequency seismic source or an alternate geophysical method such as time domain electromagnetics).

The presence of both bedrock and sediment at the glacier bed suggests that flow both by sliding and substrate deformation is at least possible at Midtdalsbreen, although sub-resolution layers of deforming till may be present where a bedrock substrate is inferred. The implication of zones of basally-frozen and unfrozen regions is consistent with the complex basal thermal regime inferred by Reinardy and others (2019), who also suggest that the entrainment and elevation of debris into the glacier requires the substrate to contain both soft and unfrozen material. The presence of thick patches of frozen sediment in the Midtdalsbreen foreland also concurs with permafrost models for this area (Etzelmüller and others, 2003). In addition to adding constraint to controls on the Midtdalsbreen flow regime, this study may have implications for other valley glaciers and presents a method by which they could be explored.

\section{Discussion and further work}

Recurrent problems in Rayleigh wave inversions include poor depth sensitivity, low resolution and ambiguous, nonunique solutions. MuLTI combines a probabilistic approach with external depth constraints, mitigating many of these issues and reducing the size of the solution space. Our probabilistic method allows the uncertainty in any chosen model to be quantified at all depth levels. The addition of depth constraints also improves vertical resolution (Killingbeck and others, 2018), and further work is required to quantify this improvement.

Nonetheless, the success of MuLTI depends inherently on the quality of the input data and their suitability for the specific target. MASW analyses fundamentally require data to be observed across an array of some minimum length, in order that low frequencies can be faithfully characterised and adequate depth sampling achieved. As such, there is always a loss of lateral resolution for the low-frequency Rayleigh wave related to the array length over which they are observed. This is why we rule out the abrupt lateral variations from our interpretation of Figure 9. We minimise this impact by reducing, where appropriate, the maximum offset in our CMPCC gathers, but the link between lateral resolution and spread-length requires refinement. Any geophysical data are also vulnerable to noise, and we note this for the low frequencies between 50 and $90 \mathrm{~m}$ in Line B. If these noisy data were neglected, we would severely restrict the data available for the inversion (Figure S5 in the supplementary material). Instead, we adopt the Bayesian paradigm in which all data are kept but with enhanced error budgets where relevant. Even with their increased uncertainties, these noisy data still provide important depth constraints to the posterior distribution. We note that our data acquisition used $10 \mathrm{~Hz}$ geophones, if we corrected our data for the instrument response we may have picked lower frequencies $(<10 \mathrm{~Hz})$ which could improve the posterior distribution at depth.

Although this paper focuses exclusively on Rayleigh wave dispersion curves derived from active source seismology, with high-frequency sources and shallow depth penetration, MuLTI can be equivalently applied to dispersion curves from passive sources (e.g., Walter and others, 2014; Picotti and others, 2017) as the Geopsy forward modelling code, used in MuLTI, has the capability to model dispersion curves with frequencies $<1 \mathrm{~Hz}$. Being richer in low frequencies $(<20 \mathrm{~Hz})$, these may enable enhanced imaging of structure beneath polar ice sheets (Aster and Winberry, 2017; Siegert and others, 2018; Yan and others, 2018). MuLTI would allow such data to be inverted with depth constraints drawn from radio-echo sounding datasets, thereby highlighting areas of large ice masses with a dynamic sediment underburden, although the algorithm would likely require adaptation to accommodate anisotropy effects.

The MuLTI framework also lends itself well to other geophysical inverse problems, where a theoretical geophysical response for a proposed model can be evaluated and compared probabilistically to observed data. An example of such an inverse problem would be the inclusion of time-domain electromagnetic (TEM) data to the existing approach, to which MuLTI could be readily adapted. Such a combined approach will be the subject of further investigations around the Midtdalsbreen margin, leading to a framework by which aquifer properties beneath large ice masses could be quantified (Hauck and others, 2011; Siegert and others, 2018).

\section{CONCLUSIONS}

The material properties of the subglacial environment exert a fundamental influence on glacier flow dynamics. These properties can be characterized by considering their shear wave velocity, Vs, obtained by inverting Rayleigh wave dispersion curves. However, conventional dispersion curve inversions lack depth sensitivity and provide solutions that are highly nonunique. Such problems are overcome with the use of our algorithm MuLTI, a transdimensional Bayesian inversion approach, which reduces the ambiguity 
in the solution space by incorporated independent depth constraints. When trialed for synthetic $\mathrm{Vs}$ data representing a small glacier underlain by sediment, inclusion of such constraints results in an order-of-magnitude improvement in the depth-averaged uncertainty in the output model, reducing it for our thickest-ice case from $\sim 1050 \mathrm{~m} \mathrm{~s}^{-1}$ to $\sim 100 \mathrm{~m} \mathrm{~s}^{-1}$. While an uncertainty of $\sim 1000 \mathrm{~m} \mathrm{~s}^{-1}$ may not impede the value of conventional inversions for distinguishing sediment and bedrock substrates, the reduced range would be critical if observations of $\mathrm{Vs}$ were to be used to quantify detailed variations in sediment properties. As such, MuLTI is an important advance in the application of Rayleigh wave inversions.

We apply MuLTI to a Rayleigh wave dataset acquired around the terminus of Midtdalsbreen, complementing it with depth-constraints derived from co-located GPR surveys. Although widely underlain by bedrock (Vs 2500 $\pm 280 \mathrm{~m} \mathrm{~s}^{-1}$ ), our data reveal that a patchy distribution of sediment is present directly beneath the glacier. These sediments are only partly frozen $\left(\mathrm{Vs} \sim 500 \mathrm{~m} \mathrm{~s}^{-1} \pm 280 \mathrm{~m} \mathrm{~s}^{-1}\right.$ ), and exist in pockets that may be up to $4 \mathrm{~m}$ thick; the sediment under-burden extends to $\sim 150 \mathrm{~m}$ up-glacier from the terminus. Our interpretation is consistent with recent studies of Midtdalsbreen, which highlight the supply of sediment to the glacier foreland and identify regions of basal sediment around the glacier front.

The seismic data used by MuLTI is supplied in the form of a dispersion curve, hence the algorithm is compatible with Rayleigh wave data obtained from either active- or passivesource surveys. Equally, depth constraints are provided as numerical inputs and can, therefore, be drawn from any external source. MuLTI is therefore applicable for a broad spectrum of seismic data types, as a means of improving the quantitative analysis for a range of contemporary glaciological problems.

\section{SUPPLEMENTARY MATERIAL}

The supplementary material for this article can be found at https://doi.org/10.1017/aog.2019.13

\section{ACKNOWLEDGEMENTS}

The MuLTI algorithm can be found at: https://github.com/ eespr/MuLTI, DOI 10.5281/zenodo.1489959. This project is funded by the UK NERC SPHERES DTP, grant NE/ L002574/1. Fieldwork was part-funded by the EVOGLAC project (University of Bergen, University of Oslo) and the research project 'Snow Accumulation Patterns on Hardangerjøkulen Ice Cap (SNAP)', itself funded by the European Union's Horizon 2020 project INTERACT, under grant agreement No 730938. Fieldwork was greatly assisted by Emma Pearce and James Killingbeck, and the support and local expertise of Kjell Magne Tangen. Richard Rigby at the University of Leeds is thanked for creating the gpdc mex file. Thomas Bodin is thanked for his advice on MCMC methods and for providing Matlab code. This paper benefited from discussions at the 2017 Glacial Seismology Summer School held at Colorado State University, sponsored by POLENET, SCAR, IGS and IACS. B. Reinardy gratefully acknowledges the support of a Bolin Centre for Climate Research grant.

\section{REFERENCES}

Åkesson H, Nisancioglu K, Giesen R and Morlighem M (2017) Simulating the evolution of Hardangerjøkulen ice cap in southern Norway since the mid-Holocene and its sensitivity to climate change. Cryosphere, 11, 281-302

Anandakrishnan S (2003) Dilatant till layer near the onset of streaming flow of Ice Stream C, West Antarctica, determined by AVO (amplitude vs offset) analysis. Ann. Claciol., 36, 283-286

Andersen JL and Sollid JL (1971) Glacial chronology and glacial geomorphology in the marginal zones of the glaciers Midtdalsbreen and Nigardsbreen, south Norway, Norsk Geogr. Tidsskr, 25 $1-38$

Andreassen LM and Winsvold H (2012) Inventory of Norwegian Glaciers. Norwegian Water Resources and Energy Directorate, rapport 38-2012, $236 \mathrm{pp}$

Armstrong M (2009) Multichannel Analysis of Surface Waves (MASW) determined surface-wave velocity profile and its relation to observation of the near-surface polar firn layers. Supervised Project Report, University of Canterbury, https://ir.canterbury.ac. nz/handle/10092/14187 (Accessed: December 2018)

Aster RC and Winberry PJ (2017) Glacial seismology. Rep. Prog Phys, 80.

Bell R (2008) The role of subglacial water in ice-sheet mass balance. Nat. Geosci., 1, 297-304

Bentley CR and Kohnen H (1976) Seismic refraction measurements of internal friction in Antarctic ice. J. Geophys. Res. 81, 15191526

Bodin T and Sambridge M (2009) Seismic tomography with the reversible jump algorithm. Geophys. J. Int., 178, 1411-1436

Bodin T and 5 others (2012) Transdimensional inversion of receiver functions and surface wave dispersion. J. Geophys. Res.: Solid Earth 117

Booth AD, Clark RA and Murray T (2010) Semblance response to a ground-penetrating radar wavelet and resulting errors in velocity analysis. Near Surf. Geophys. 8, 235-246

Booth AD, Clark RA and Murray T (2011) Influences on the resolution of GPR velocity analyses and a Monte Carlo simulation for establishing velocity precision. Near Surf. Geophys., 9, 399-411

Booth AD and 6 others (2012) Thin-layer effects in glaciological seismic amplitude-versus-angle (AVA) analysis: implications for characterising a subglacial till unit, Russell Glacier, West Greenland. Cryosphere, 6, 909-922

Booth AD and 5 others (2013) A comparison of seismic and radar methods to establish the thickness and density of glacier snow cover. Ann. Glaciol., 54, 73-82

Bouchon M and Aki K (1977) Discrete wave-number representation of seismic-source wave fields. Bull. Seismol. Soc. Am., 67, 259277

Christoffersen P, Bougamont $M$, Carter SP, Fricker HA and Tulaczyk S (2014) Significant groundwater contribution to Antarctic ice streams hydrologic budget. Geophys. Res. Lett., 41, 2003-2010

Diez A and 7 others (2014) Influence of ice crystal anisotropy on seismic velocity analysis. Ann. Glaciol., 55, 97-106

Dou S and Ajo-Franklin JB (2014) Full-wavefield inversion of surface waves for mapping embedded low-velocity zones in permafrost. Geophysics, 79, 107-124

Etzelmüller B and Hagen JO (2005) Glacier-permafrost interaction in Arctic and alpine mountain environments with examples from southern Norway and Svalbard. In Harris $C$ and Murton JB eds. Cryospheric systems: glaciers and permafrost. Geological Society, London, Special Publication, 242, 11-27

Etzelmüller B, Berthling I and Sollid JL (2003) Aspects and concepts on the geomorphological significance of Holocene permafrost in southern Norway. Geomorphology, 52, 87-104

Foti S and 7 others (2015) Uncertainties in VS profiles from geophysical tests and their influence on seismic ground response analyses: results from the InterPACIFIC blind Test. 6th 
International Conference on Earthquake Geotechnical Engineering. Christchurch, NZ

Gazetas G (1982) Vibrational characteristics of soil deposits with variable wave velocity. Int. J. Numer. Anal. Methods Geomech., 6, 1-20

Gucunski N and Woods RD (1992) Numerical simulation of the SASW test. Soil Dyn. Earthq. Eng., 11, 213-227

Hauck C, Bottcher M and Maurer H (2011) A new model for estimating subsurface ice content based on combined electrical and seismic data sets. Cryosphere, 5, 453-468

Hayashi K and Suzuki H (2004) CMP cross-correlation analysis of multi-channel surface-wave data. Explor. Geophys., 35, 7-13

Hofstede C and 7 others (2018) Physical conditions of fast glacier flow: 2. Variable extent of anisotropic ice and soft basal sediment from seismic reflection data acquired on Store Glacier, west Greenland. J. Geophys. Res. Earth Surf., 123, 349-362

Johansen TA, Digranes P, Van Schaack M and Lønne I (2003) Seismic mapping and modeling of near-surface sediments in polar areas. Geophysics, 68, 566-573

Killingbeck SF, Livermore PW, Booth AD and West LJ (2018) Multimodal layered transdimensional inversion of seismic dispersion curves with depth constraints. Geochem. Geophys. Geosyst. 19, 4957-4971

King EC and Jarvis EP (2007) Use of shear waves to measure poisson's ratio in polar firn. J. Environ. Eng. Geoph., 12, 15-21

Kneisel C, Hauck C, Fortier R and Moorman B (2008) Advances in geophysical methods for permafrost investigations. Permafrost Periglac. Processes, 19(2), 157-178

Kulessa B and 10 others (2017) Seismic evidence for complex sedimentary control of Greenland Ice Sheet flow. Sci. Adv., 3, 1603071

Lindbäck K and 8 others (2018) Subglacial topography, ice thickness, and bathymetry of Kongsfjorden, northwestern Svalbard. Earth Syst. Sci. Data, 10, 1769-1781

Livermore PW, Fournier A, Gallet $\mathrm{Y}$ and Bodin T (2018) Transdimensional inference of archeomagnetic intensity change. Geophys. J. Int., 215(3), 2008-2034 (doi: 10.1093/gji/ggy383)

Murray T, Booth AD and Rippin DM (2007) Water-content of Glacier-Ice: limitations on estimates from velocity analysis of surface ground-penetrating radar surveys. J. Environ. Eng. Geophys., 12, 87-99

Park CB (2005) MASW horizontal resolution in 2D shear-velocity (Vs) mapping. Open-File Report 2005-4, Lawrence: Kansas Geologic Survey February 17, 2005.

Park CB, Miller RD and Xia J (1998) Imaging dispersion curves of surface waves on multi-channel record. SEG Technical Program Expanded Abstracts, January 6, 1998, 1377-1380

Park CB, Miller RD and Xia J (1999) Multichannel analysis of surface waves. Geophysics, 64, 800-808

Park CB, Miller RD and Xia J (2001) Offset and resolution of dispersion curve in multichannel analysis of surface waves (MASW). Symposium on the Application of Geophysics to Engineering and Environmental Problems, SSM4-SSM4

Peters LE and 5 others (2008) Seismic detection of a subglacial lake near the South Pole, Antarctica. Geophys. Res. Lett. 35

Picotti S, Vuan A, Carcione JM, Horgan HJ and Anandakrishnan S (2015) Anisotropy and crystalline fabric ofWhillans Ice Stream (West Antarctica) inferred from multicomponent seismic data. J. Geophys. Res.: Solid Earth 120, 4237-4262

Picotti S, Francese R, Giorgi M, Pettenati F and Carcione JM (2017) Estimation of glacier thicknesses and basal properties using the horizontal-to-vertical component spectral ratio (HVSR) technique from passive seismic data. J. Glaciol., 63, 229-248

Podolskiy EA and Walter F (2016) Cryoseismology. Rev. Geophys., 54, 708-758

Preiswerk LE and Walter F (2018) High-frequency $(>2 \mathrm{~Hz})$ ambient seismic noise on high-melt glaciers: green's function estimation and source characterization. J. Geophys. Res. Earth Surf., 123, 1667-1681
Reinardy BTI, Leighton I and Marx PJ (2013) Glacier thermal regime linked to processes of annual moraine formation at midtdalsbreen, southern Norway. Boreas, 42, 896-911

Reinardy BTI and 8 others (2019) Pervasive cold ice within a temperate glacier - implications for glacier thermal regimes, sediment transport and foreland geometry. Cryosphere, 13, 827-843

Richart FE, Hall JR and Woods RD (1970) Vibrations of soils and foundations. Int. Ser. Theoretical Appl. Mechanics 1970

Saintenoy A and 6 others (2013) Deriving ice thickness, glacier volume and bedrock morphology of the Austre Lovénbreen (Svalbard) using Ground-penetrating Radar. Near Surf. Geophys., 11, 253-261

Shen W and 10 others (2018) The crust and upper mantle structure of central and west Antarctica from Bayesian inversion of Rayleigh wave and receiver functions. J. Geophys. Res.: Solid Earth, 123, 7824-7849

Siegert MJ and 7 others (2018) Antarctic subglacial groundwater: a concept paper on its measurement and potential influence on ice flow. Geological Society, London, Special Publications, 197-213

Stearns LA and Van der Veen CJ (2018) Friction at the bed does not control fast glacier flow. Science, 361, 273-277

Stokoe KH, Wright GW, James AB and Jose MR (1994) Characterization of geotechnical sites by SASW method. In Geophysical characterization of sites. ISSMFE Technical Committee 10.

Temminghoff M, Benn DI, Gulley JD and Sevestre H (2018) Characterization of the englacial and subglacial drainage system in a high Arctic cold glacier by speleological mapping and ground-penetrating radar. Geogr. Ann.: Ser. A, Phys. Geo., 1-20

Thiel E and Ostenso NA (1961) Seismic studies on Antarctic ice shelves. Geophysics, 26, 706-715

Tsoflias GP and 6 others (2008a) Firn and shallow ice profiling at Jakobshavn Glacier using dispersed seismic surface waves. AGU Fall Meeting Abstracts

Tsoflias GP, Ivanov J, Anandakrishnan S and Miller R (2008b) Use of active source seismic surface waves in glaciology. 21st EEGS Symposium on the Application of Geophysics to Engineering and Environmnetal Problems.

Tsuji T, Johansen TA, Ruud BO, Ikeda T and Matsuoka T (2012) Surface-wave analysis for identifying unfrozen zones in subglacial sediments. Geophysics, 77, 17-27

Walter F, Chaput J and Lüthi MP (2014) Thick sediments beneath Greenland's ablation zone and their potential role in future ice sheet dynamics. Geology, 42, 487-490

Wathelet M (2005) Array recordings of ambient vibrations: surfacewave inversion. (PhD Diss., Liége University, 161)

Wathelet M, Jongmans D and Ohrnberger M (2004) Surface wave inversion using a direct search algorithm and its application to ambient vibration measurements. Near Surf. Geophys., 2, 211-221

Willis IC, Fitzsimmons CD, Melvold K, Andreassen LM and Giesen RH (2012) Structure, morphology and water flux of a subglacial drainage system, Midtdalsbreen, Norway. Hydrol. Processes, 26, 3810-3829

Xia J, Miller RD and Park CB (1999) Estimation of near-surface shear-wave velocity by inversion of Rayleigh waves. Geophysics, 64, 691-700

Xia J, Miller RD, Park CB and Tian G (2003) Inversion of high frequency surface waves with fundamental and higher modes. J. Appl. Geophys., 52, 45-57

Yan P and 5 others (2018) Antarctic ice sheet thickness estimation using the horizontal-to-vertical spectral ratio method with single-station seismic ambient noise. Cryosphere, 12, 795-810

Young Kim K and 5 others (2010) Seismic and radar investigations of Fourcade Glacier on King George Island, Antarctica. Polar Res., 29, 298-310

Zimmerman RW and King MS (1986) The effect of the extent of freezing on seismic velocities in unconsolidated permafrost. Geophysics, 36, 1285-1290 